\title{
AC 2007-3001: NEW EDUCATIONAL SERVICES BASED ON AMBIENT INTELLIGENCE AND BIOMETRIC APPLICATIONS ON DISTANCE AND ONLINE EDUCATION
}

Manuel Castro, Universidad Nacional de Educacion a Distancia

Rosario Gil, Universidad Nacional de Educacion a Distancia

Sergio Martin, Universidad Nacional de Educacion a Distancia

Elio Sancristobal, Universidad Nacional de Educacion a Distancia

Pablo Losada, Universidad Nacional de Educacion a Distancia

Gabriel Diaz, Universidad Nacional de Educacion a Distancia

juan peire, Universidad Nacional de Educacion a Distancia 


\title{
New Education Services based on Ambient Intelligence and Biometric Applications on Distance and on-Line Education
}

\begin{abstract}
This paper addresses the design and implementation of new examination systems for distance learning in two different scenarios: the first one consists of the implementation of a traditional examination in the same way as it is done in many distance learning studies having all the students moving to the classroom for the final e-learning process: the examination; and the second one is a new design for remote or on-line examination, which is based on security issues and new technology applications. Concerning this new design we are in the final step of definition and implementation.
\end{abstract}

\section{Background}

Nowadays new services are being developed to blend distance and on-line learning with a level of commitment and specification required by the new global world.

Some of these services developed try to facilitate the examinations allowing, on the one hand, the remote on-line examination and, on the other hand, a better control in the examination classrooms. It will use ambient intelligence and biometry as the cornerstone of these services.

At university a student enters in an exam's class and an RFID sensor will detect his presence in the enclosure through his passive RFID tag. Once the student is located and identified the system will print a personalized exam in which will show the place where that student must sit down.

On the other hand, new services are being developed to support remote or distance on-line test in examinations. Nowadays there is a high risk of fraud on the students' side since they can imagine a thousand of techniques to cheat in an exam. We are affronting an important challenge adding all kind of measures to avoid the fraud. We are using biometrics techniques to assure the identity of users during the whole exam.

\section{RFID on examination classrooms}

These days there is a waste of time preparing all the elements will take part in an exam. The first problem will be to distribute all the students to their respective class, because each student will have to do a specific exam for a particular subject and each student will probably arrive at the university at different time.

This problem becomes to be important when the number of students increase more than two thousand. Then it is impossible to control the accesses of all the students.

We propose a solution that will provide the identification of each user in real time ${ }^{1}$. Each student will carry an RFID tag inside the student card where will be stored an ID. When students walk along an RFID reader the system will obtain their identities. At the end of the corridor each 
student will have a customized exam. Each exam must be different for each subject and it must be different several times because students can do an exam in different hour.

Our system works with the following functionalities:

- It can identify all the students in real time.

- Print a specific exam for each student.

- Control when a student finishes his exam. Thanks to this system we will be able to know if a student tries to leave the class without handing in his exam.

The next challenge is assure the identity of each student. We already know all the students are going to their examination classes with their RFID cards but in fact anyone could get one of these cards and tries to do an exam for other students. The solution could be to incorporate biometric technology in our system.

The RFID reader corridor will be equipped with video cameras, which will provide the identification of all the students' faces while students are walking along the corridor. The system will compare the present image to a database. It will try to assure us of a student with his RFID tag is really who he says to be (Fig. 1).
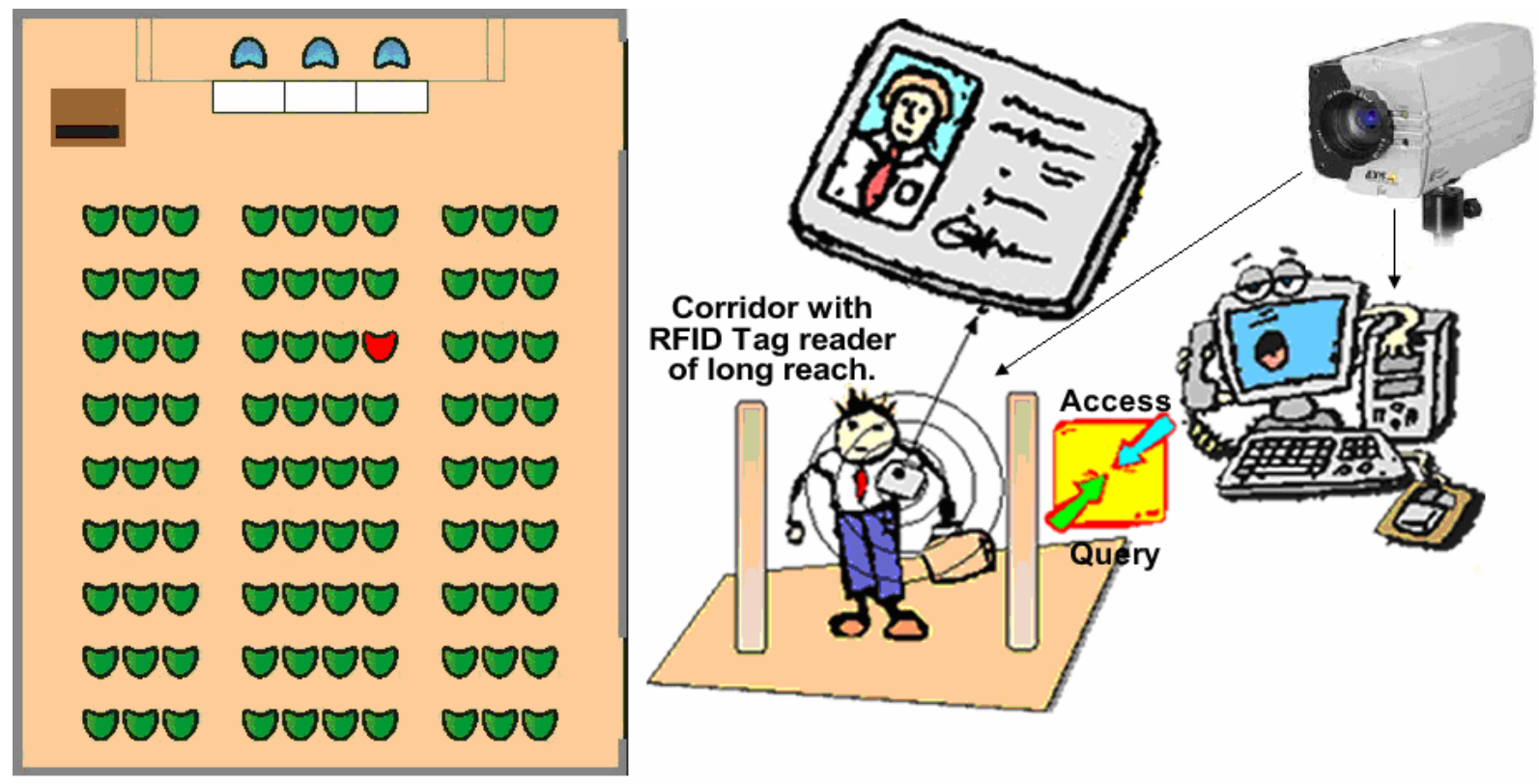

Fig.1. Figure of the procedure of our system. A user is identified and registered at the entrance and exit of the examination enclosure.

In short, the main contributions ${ }^{2}$ of this system are:

- An examination room will be able to receive a high number of students simultaneously.

- Students will not have to wait for a long time to enter in the examination classroom.

- Each entry and leaving on the students side room will be suitable registered.

- It allows printing a customized exam in real time.

- This system will simplify procedures for students and staff.

- The leaving of students without handing in their exams will be recognized easily. 
RFID tags provide a great solution for the examination problem due to their characteristics: robustness, speed of reading, simultaneous reading, security, programmable tags and it is not necessary a direct line of vision.

\section{Biometric application on remote and on-line examination}

The next step in the examination environment is to reduce the number of people who have to control students and to reduce all the logistic and infrastructure. That is to remove the sheets of an exam, in order to do an exam by web. Then an exam will be moved to students' house or why not to a cybercafé. The advantages are easily recognized:

- We save money in staff and infrastructure.

- Students have more facilities to do an exam because they do not have to go to the examination class. As a consequence, people who could not take an exam because they lived in other country or they had some handicaps, now they will be able to do an exam.

- As a consequence students also save money because they do not have to move to the university.

Therefore, the new system will have to find new solutions in how to control an enclosure that a student chooses freely. Of course, this new enclosure is going to be less secure and controllable than in university class. Biometric technologies ${ }^{4}$ will be able to make possible the developed of a new system where a student will be controlled during the whole exam. At the beginning of an exam each student must be identified and afterwards he will be able to answer his exam being controlled by biometric technologies ${ }^{6}$.

During an exam, we can distinguish two phases ${ }^{5}$ : Identification and control of each student during the whole exam. Before an exam, we propose a previous step, that is an enroll step. When a student is registered by Internet or in person at the university, his fingerprint ${ }^{3}$ is captured by biometric devices and it is allocated an ID to that student. This ID will be stored in RFID tag.

The advantages of this previous step are: to add more security for the information, to avoid problems later that they couldn't be resolved at the exam moment, also as the biometric characteristics can change throughout the time we assure to have recent samples. If we do this previous step every year we will reduce the false rejection rate.

In this way after the registration period, a student will have an RFID card where it will be stored an ID. It will also have created databases with the biometric characteristic and ID's RFID for all the students.

\section{Biometric system: Architecture}

As we have said above, our system has two phases: The first one will be to find the identity of a student ${ }^{7}$ before doing his exam and the second phase will be to control each student during the rest of the exam time. 
In the first phase, the procedure is the next one: When a student is in his room he or she enters in the exam application hitting his biometric mouse ${ }^{3}$ and moving closer his RFID card to the RFID Reader. It will automatically access to the fingerprints and RFID IDs databases and it will compare the recent fingerprint sample and RFID ID to their respective database. In the fingerprint database there will be a comparison 1:N, being $\mathrm{N}$ all the students who are registered ${ }^{8}$. If it finds two samples with a high correlation then we will be able to say that both samples are equal and both are from the same person. If the RFID ID coincides in his database then that student will be let to do his exam.

The diagram of our system could be the next one in the Figure 2.

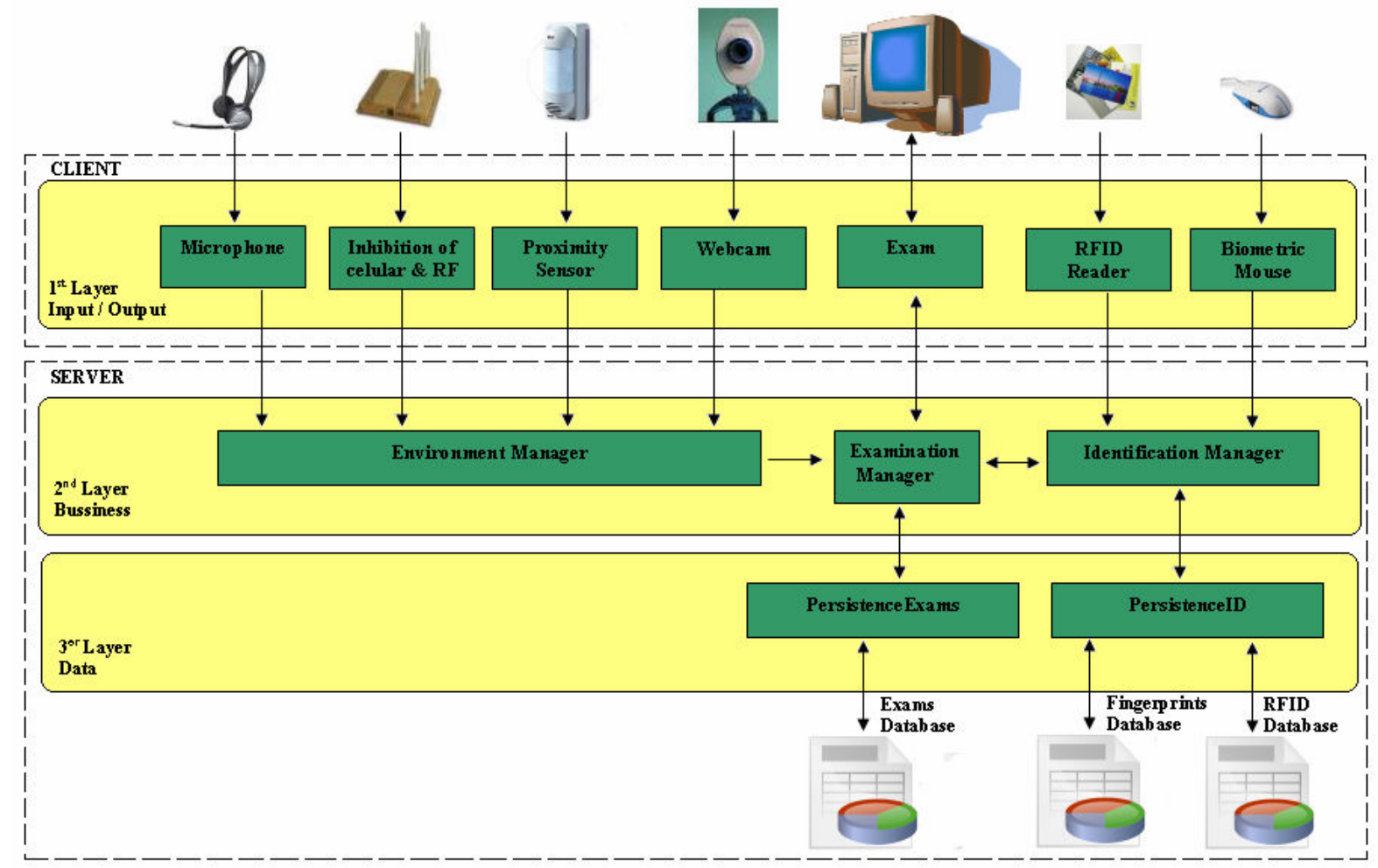

Fig. 2. Proposal of biometric remote system for examination.

Our biometric system can be made of three layers. In the first layer there will be all the peripherals that will analyze the environment where a student is doing his exam. There will be a microphone, an inhibition of cellular and RF, a proximity sensor and a webcam. In this layer there will also be the peripherals that will identify each student, which are an RFID Reader and a Biometric mouse. Finally there will be any browser where will show exams and where each student will be able to answer his exam. In the second layer there will be three managers which will control the environment, the examination and the identification of each student. In the third layer there will be three databases for the questions and answers of an exam, fingerprints and RFID IDs of all the students.

The main characteristics are:

- PC embedded programs that will only allow using the necessaries applications to do an exam. 
- Inhibition of cellular phone and RF that will avoid using banned devices.

- Audio Controller: This module registers with a microphone all the sounds produced in a room at the same time that avoids with an earpiece that a student hears sounds from other people.

- Proximity and Visual Controller: These sensors have the function to control the presence of any person inside a room. We will be able to do this with a proximity sensor which can differentiate between more than one people in a room. On the other hand with a webcam we can study the enclosure.

- RFID Reader: This sensor obtains information about an user reading an RFID tag incorporated in a student card.

- Biometric mouse ${ }^{3}$ : This device will capture a sample at the beginning of an exam. This sample will be compared to fingerprints database. If there is a match then the exam will start, else it will capture other samples and after few attempts the application will be closed.

- There will be three databases: Fingerprints database, RFID IDs and Exams database. This last one will have different exams and their respective answers. In this way it will mark all the exams automatically.

In short we will provide an enclosure that will be the most secure than we can. On one hand with PC embedded programs and on the other hand with a control of the perimeter of a room by means of devices that assure that a student is alone in his room and he is not cheating. These devices could be proximity and visual sensors, inhibition of cellular phone, inhibition of RF, biometric mouse, RFID reader and audio controller towards noises.

Our main block is the Biometric mouse. In this way, it uses a Software Development Kit (SDK) together with our own functions that will be implemented in $\mathrm{C}++$. This means that we have to program in no open code on the client side. However, on the server side it will be implemented in Java. Then our system works in the following way:

1) A student opens a browser and he enters in the exam web.

2) As RFID Reader as Biometric Mouse will capture their respective data sending them to the Identification Manager module.

3) The Identification Manager module decides if both data are correct asking the PersistenceID module, in which will compare the recent ID and fingerprint sample to the rest of their respective database.

4) If the user is accepted the Examination Manager module will be called by the Identification Manager module. This module will look for a specific exam for that student.

5) During the whole exam there will be different devices that will control the enclosure, these will be: a microphone, an inhibition of cellular and RF, a proximity sensor and a webcam.

6) The module Environment Manager module will control these peripherals. When some of them warn the Environment Manager module this will mean that a student is trying to cheat, and then the module Examination Manager will close the exam application.

7) Finally when a student finishes his exam, if there hasn't been any problem, each user will send their exams and they will be marked in the Examination Manager because in the same database there will be as questions as answers. 
We have to take into consideration in our system the following:

- It must be controlled that an user can't replace himself with other person during the exam process, so that we will check the Biometric mouse several times in the exam.

- We already said that the new enclosure was to be less security than a traditional environment. Although our system has many devices for control the room, it's impossible to think that we have resolved all the problems. We can guarantee that any students won't be able to share information because each student will have a customized exam. Then, although an exam starts in different hour in one day, we will be reducing the possibility of cheating. But we can't resolve the possibility that a student can read his own notes or a book. This is not a big problem in technical subjects because the use of books doesn't guarantee a successful exam.

\section{Conclusions}

Nowadays, we look for a solution that can provide our examination room with more security and effectiveness as much as it is possible. An RFID system will be able to resolve many of the current problems. It will reduce the time of waiting for accessing to the class and it will have identified all the students in real time.

The next challenge is to make possible that a student can do an exam in his house ${ }^{9}$. In this case we combine the RFID Technology with Biometric Technology. A student will be able to access to his exam by web and by means of his RFID card and his biometric mouse. In every time he will be controlled by his fingerprint and other devices so that we will try to assure that a student is alone.

\section{Acknowledgements}

The authors would like to acknowledge to the Spanish Science and Education Ministry and the Spanish National Plan I+D+I 2004-2007 the support for this paper as the project TSI200508225-C07-03 "mosaicLearning: Aprendizaje electrónico móvil, de código abierto, basado en estándares, seguro, contextual, personalizado y colaborativo".

\section{Bibliography}

1. Martín, S., Castro, M., Peire, J. et al. Experiencias e introducción de dispositivos móviles en la Enseñanza a Distancia. Ubiquitous Computing \& Ambient Intelligence, Granada Spain, 2005.

2. Rivilla, I., Castro, M. et al. Development and implementation of a collaborative environment for education. eAdoption and the Knowledge Economy - Issues, Applications, Case Studies. Editores: Cunningham, P y Cunnningham, M. Ed. IOS Press, Amsterdam Holanda, 2004.

3. Uludag, U. and Jain, A.K. "Attacks on Biometric Systems: A Case Study in Fingerprints". Department of Computer Science and Engineering. Michigan State University, East Lansing, MI, USA 48824.

4. Conry-Murray, A. "Biometrics. Biometrics adds a unique identifier to network authentication". NetworkMagazine.com

5. Liu, S. and Silverman, M. "A Practical Guide to Biometric Security Technology". IEEE Computer Society. February 2001. 
6. Blackburn, D.M. "Biometrics 101". "Introduction to Biometrics" section of the Biometrics Catalog. Federal Bureau of Investigation. Department of Defense Tutorials. March 2004. Available on January 15th, 2007. http://www.biometricscatalog.org/biometrics/biometrics_101.pdf

7. Tapiador, M. and Sigüenza, J.A. "Tecnologías biométricas aplicadas a la seguridad". Ed. Ra-Ma, 2005.

8. Chirillo, J. and Blaul, S. "Implementing Biometric Security". Ed. Wiley, 2003.

9. Wayman, J., Jain, A, Maltoni, D. and Maio, D. "Biometric Systems: Technology, Design and Performance Evaluation". Ed. Springer, 2005. 